\title{
The analysis of deformations of the frame in a basic minibus and a low floor minibus
}

\author{
Tautvydas Pravilonis*, Edgar Sokolovskij**, Vytenis Surblys*** \\ *JSC "ALTAS komercinis transportas" Centrine str., 30,Vilnius, Lithuania, E-mail: t.pravilonis@yahoo.com \\ **Vilnius Gediminas Technical University, Basanavičiaus str., 28, Vilnius, Lithuania; E-mail: edgar.sokolovskij@vgtu.lt \\ ***Vilnius Gediminas Technical University, Basanavičiaus str., 28, Vilnius, Lithuania; E-mail: vytenis.surblys@vgtu.lt
}

cross $^{\text {ref }}$ http://dx.doi.org/10.5755/j01.mech.23.3.14480

\section{Introduction}

While examining issues related to safety of vehicles, not only the critical parameters of their movement [1] or circumstances of traffic events [2] shall be analyzed; in addition, safety and strength of the vehicle's construction shall be analyzed upon striving to make sure that it really ensures a safety both of the driver and the passengers [3]. In case of a frontal impact, the driver usually suffers heavier injuries, as compared to the passengers, and in case of a lateral impact, the injuries of the driver are less serious [4]. A produced vehicle should meet the safety requirements; in addition, it should be reliable and durable, because a weakened construction of the vehicle does not duly protect persons inside the vehicle in case of a traffic event and they may suffer heavy injuries or even perish.

Problems related to the design safety of vehicles also concern the interests of enterprises involved in low-rate production of vehicles, because such enterprises change the design of vehicles and introduce various structural modifications of their bodies, frames as well as other changes that directly affect the design safety of the vehicle. In this specific case, a frame of a low floor minibus is discussed upon.

As it is stated by Parka et al. [5], a ladder type frame is a key structural part of a vehicle, because it absorbs the striking energy. The mass of the frame forms about 10 $\%$ of the total mass of the vehicle. Usually frames are produced of steel. Steel is used for their production, because it effectively absorbs the striking energy on accidents; in addition, production of steel is not too complicated. To ensure sufficient strength of frames, longitudinal and transverse rods as well as various strengthening elements are used: they are united into an integral structure by welding.

The weakest parts of a bus that require a great attention are its roof and sides [6], so in low floor buses (where the frame is lowered by $300 \mathrm{~mm}$ ), ensuring of a reliable and strong structure connecting the frame with sides is of a great importance. Such a connecting construction consists of several rectangular pipes of different diameters welded with each other and connected both the frame and the sides of the bus.

Upon striving to ensure sufficient strength and good mechanical properties of the welded structures, nanotechnologies are applied in welding. It was found that using nanoparticles in laser welding causes a considerable improvement of the strength of welding seams [7]. An exclusive peculiarity of the new technology is addition of nonfusing powder (for example, titanium carbide) with nanoparticles onto the connection to be welded. The said technology enables controlling the metal solidification in the welding process.

Another important aspect in vehicle design and manufacturing is the safety tests of their structural parts. To save funds allotted for expensive tests of structural parts, numerical methods and modeling programs usable for dynamic vehicle body analysis are applied in the design phase. According to the obtained results, it may be possible to establish the weak points of the body that can break while affected by high loads [8].

In addition, modeling programs may be used for identifying the parameters that mostly affect deformation of the structure. It may be accomplished by modeling a collision of a vehicle upon applying the finite element method (FEM). The vehicle is divided to finite elements, the links between individual elements are described and the initial data (such as the weight, the energy absorption coefficient, and the depth of the body deformation) are entered. On computer-aided modeling, the initial data are being altered and the obtained results may show that reduction of the vehicle weight can cause reducing the depth of the body deformation, when the value of the energy absorption coefficient is constant. For optimization of the vehicle load carrying structure, its mass may be reduced, thus cutting the costs related to raw materials and improving the cost-effectiveness of the vehicle without prejudice to the strength of the structure [9].

Other results of modeling obtained from the simulation of deformation of the structure enable substantiating the above-provided statement that the most danger to a traffic participant is caused by a lateral impact against a vehicle [10]. While comparing the results of a frontal impact, a rearend impact and a lateral impact, it may be stated that the heaviest injuries of traffic participants take place when the impact is concentrated to the lateral part of the vehicle.

Dzerkelis et al. [11] in their paper discussed upon the deformations of the body affected by static forces and found that the results obtained by numerical methods and the results obtained by modeling differ almost twice. Such a difference of the obtained results may be caused by certain preconditions accepted upon striving to simplify the construction. However, the results obtained in the first and in the second way do not exceed the yield point of the material.

\section{Calculations of the frame resistance}

There is calculating the frame with straight spar, connected in transverse (ladder-type frame). In the frame calculations, the greatest attention should be paid to calculation of the frame bending. Calculation of the subframe cross-bearer is started from calculation of bending because, 
when the load is symmetric, the longerons are loaded and deformed symmetrically, but the rods are neither loaded nor deformed. So, the conditions for calculating preliminary sizes of the frame elements upon applying methods of statically computable systems and for making a decision on the need in variable diameter longerons are formed [12].

The calculation of bending forms the conditions for choosing the sizes of cross-sections of the longerons and establishing their preliminary geometrical characteristics. Sizes of the frame elements are established according to their maximum tensions on bending.

The transversal forces and the bending moments that affect the frame are calculated for each segment (Fig. 1) according to Eqs. (1) and (2), respectively.

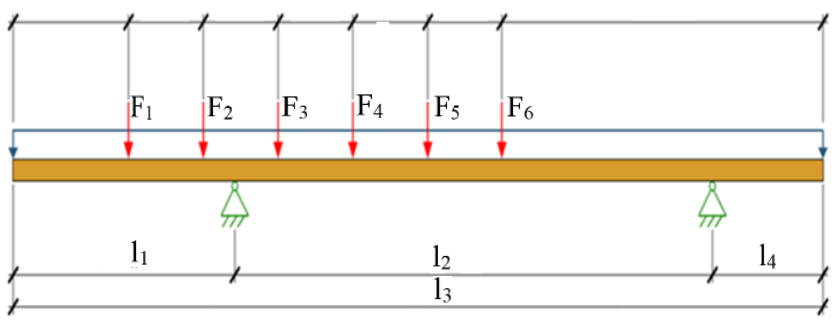

Fig. 1 The frame calculation scheme

$$
\begin{aligned}
& Q=\sum F_{i}, \\
& M=\sum F_{i} l_{i},
\end{aligned}
$$

where $F_{i}$ is the forces acting in a segment; $l_{i}$ is the length of the segment.

If the bending moments that affect the frame of a minibus are known, the maximum tensions shall be calculated according to Eq. (3):

$$
\sigma_{\max }=\frac{\left|M_{\max }\right|}{W_{x}},
$$

where $\sigma_{\max }$ is a maximum permissible tension of the structure; $M_{\max }$ is the maximum dangerous section bending moment; $W_{x}$ the cross-section resistance moment.

After the assessment of the forces and moments affecting the subframe, the deflection caused by external loads and deformation of the frame is assessed as well. The deflection is assessed according to Eq. (4):

$$
k=\sum \int \frac{M_{i} M_{j}}{E I} d x
$$

where $M$ is bending moment; $E$ is elasticity modulus; $I$ is moment of inertia.

For assessing all forces that affect deflection of the structure, Eq. (5) is used:

$$
\begin{aligned}
& k=\sum \int \frac{M_{i} M_{j}}{E I} d x+\sum \int \frac{T_{i} T_{j}}{G I_{S}} d x+ \\
& +\sum \int \frac{F_{i} F_{j}}{E A} d x+\sum \int \frac{q_{i} q_{j} A}{G h},
\end{aligned}
$$

where $T$ turning moment; $G$ is shear modulus; $F$ axial force;
$A$ is area of cross-section; $q$ is the distributed load.

\section{Computer - aided frame modelling}

To assess the strength of the construction of a low floor minibus and to establish its difference from the strength of the construction of a basic minibus, several modeling operations shall be performed. Primary database parameters shown in Table.

Primary database parameters which was used for modelling

\begin{tabular}{|l|c|}
\hline \multicolumn{1}{|c|}{ Parameter } & Value \\
\hline Frame length & $7340 \mathrm{~mm}$ \\
\hline Frame width & $950 \mathrm{~mm}$ \\
\hline The main frame beam section dimensions & $\begin{array}{c}80 \mathrm{~mm} \times 80 \\
\mathrm{~mm}\end{array}$ \\
\hline Steel yield strength & $710 \mathrm{MPa}$ \\
\hline Steel grade (selected from SolidWorks Library) & AISI 4340 \\
\hline The factory-frame operating split vertical lo & $20,23 \mathrm{kN} / \mathrm{m}$ \\
\hline Vertical force operating in low-floor sub-frame & $26,39 \mathrm{kN} / \mathrm{m}$ \\
\hline $\begin{array}{l}\text { Frame speed striking an obstacle front and side } \\
\text { parts }\end{array}$ & $50 \mathrm{~km} / \mathrm{h}$ \\
\hline
\end{tabular}

Modeling is accomplished by „Ansys“ program upon using its complement „Explicit Dynamics“. It is an alternative method and its using ensures the results very close to the results obtained in the experimental way [13].

If a model is a spatial system formed of beams and hulls, such a model is practically unsolvable by usual methods, so the finite element methods are applied in this case [14]. In „Ansys“ program chosen for the modeling, the calculations are carried out upon applying Newmark method.

The equilibrium equation:

$$
\begin{aligned}
& {[M] \ddot{U}+[C] \dot{U}+[K] U=R,} \\
& \dot{U}_{i+1}=\dot{U}_{i}+\left[(1-\delta) \dot{U}_{i}\right]+\left[(1-\delta) \dot{U}_{i}+\delta \ddot{U}_{i+1}\right] \Delta t, \\
& U_{i+1}=U_{i}+\dot{U}_{i} \Delta t+\left[\left(\frac{1}{2}-\alpha\right) \ddot{U}_{i+\alpha} \cdot \ddot{U}_{i+1}\right] \Delta t^{2}, \\
& \ddot{U}_{i+1}+C \dot{U}_{i+1}+K \dot{U}_{i+1}=R_{i+1},
\end{aligned}
$$

where $\ddot{U}$ is acceleration; $\dot{U}$ is speed; $U$ is displacement; $[M]$ is the mass matrix; $[C]$ is the damping matrix; $[K]$ is the stiffness matrix; $R$ is the generalized excitation (force) term; $t$ is the time step; $\delta$ is variation; $\alpha$ is the number of elements.

For solving Eq. (9), first of all, the value of acceleration is found from Eq. (8); the said value is inserted in Eq. (7). So, after establishing the acceleration and the velocity, only the shift remains unknown. The found values of the acceleration and the velocity are inserted in Eq. (9) and then the shift is found from it.

Because the consequences of a frontal impact are very dangerous [15], the first modeling operation is accomplished for the frame of a basic minibus that knocks against an immovable obstacle. During simulation frame speed was taken into computer program as the main parameter, e.g. 
$50 \mathrm{~km} / \mathrm{h}$. Through the simulation it was important to identify what stress, strains occur when the frame hits the obstacle at a specific speed.

$50 \mathrm{~km} / \mathrm{h}$ moving speed was chosen taking into account the recommendations of the independent organization Euro - NCAP (European New Car inspection program). Also $50 \mathrm{~km} / \mathrm{h}$ speed is the average speed in town. Therefore, the aim was to determine what underframe stresses and deformations appear while frame is moving in average city speed and hits the obstacle. After simulations it appears that slower moving speed will result in lower stresses and deformations.

Mowing with the velocity of $50 \mathrm{~km} / \mathrm{h}$ and knocking against an immovable obstacle show in Fig. 2 (the overlap between the obstacle and the frame is $40 \%$ ).

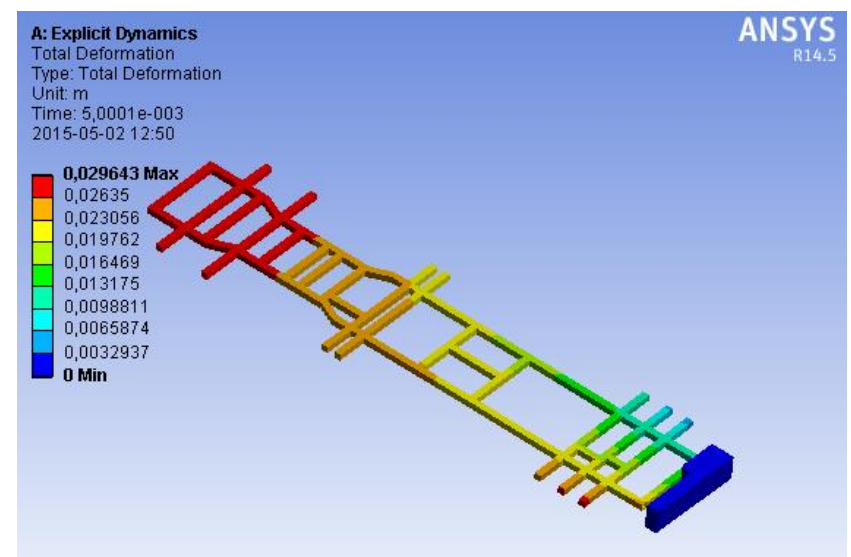

Fig. 2 The deformation of the frame in a basic minibus caused by a frontal impact against an obstacle

The maximum deformation of the frame in a basic minibus is $29.64 \mathrm{~mm}$ (Fig. 2). When the frame knocks against an obstacle, the appeared maximum tensions achieve the value of $1282 \mathrm{MPa}$ (Fig. 3).

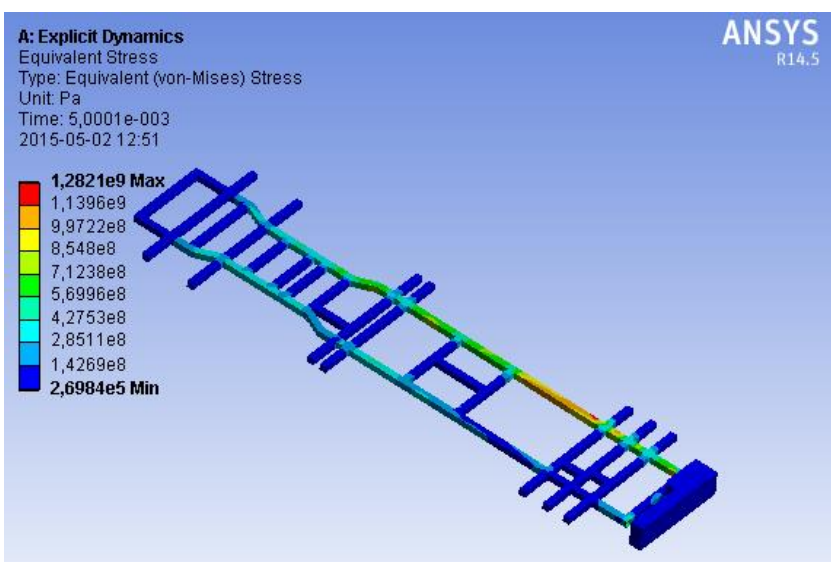

Fig. 3 The distribution of tensions in the frame of a basic minibus caused by a frontal impact against an obstacle

Upon analogous conditions, the modeling operation is accomplished for the frame of a low floor minibus that knocks against an immovable obstacle while moving with the velocity of $50 \mathrm{~km} / \mathrm{h}$ (Fig. 4).

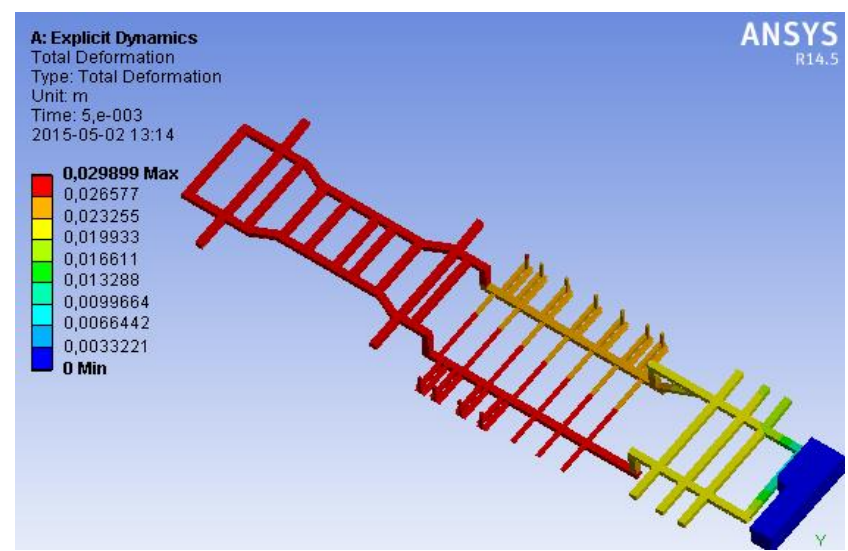

Fig. 4 The deformation of the frame in a low floor minibus caused by a frontal impact against an obstacle

The maximum deformation of the frame in a low floor minibus is $29.89 \mathrm{~mm}$ (Fig. 4). While comparing the deformations of the frames in a basic minibus and a low floor minibus, it may be seen that the deformation of the frame in the low floor minibus exceeded the deformation of the frame in the basic minibus by $0.25 \mathrm{~mm}$ only. However, the maximum tensions appeared in frame of the low floor minibus on its knocking against an obstacle were $259 \mathrm{MPa}$ only (Fig. 5). So, these tensions are over 4 times less, as compared to those appeared in the frame of the basic minibus.

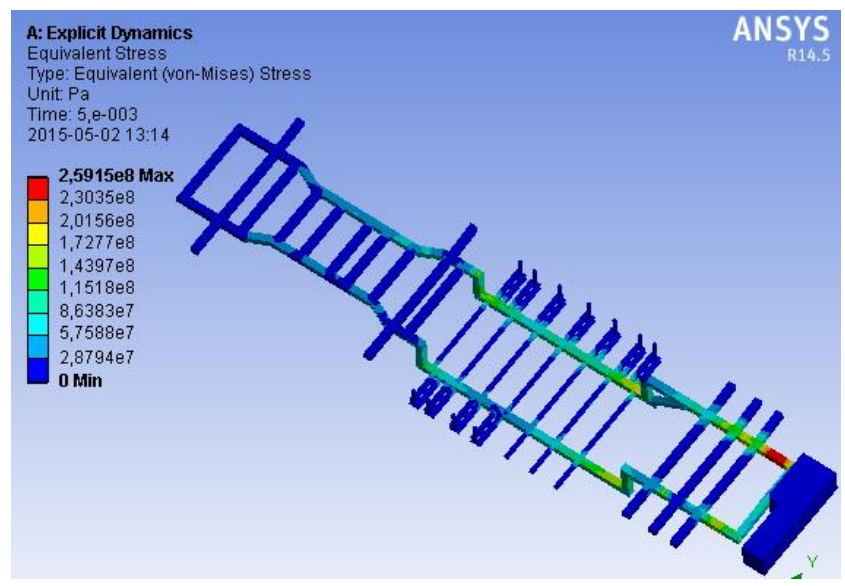

Fig. 5 The distribution of tensions in the frame of a low floor minibus caused by a frontal impact against an obstacle

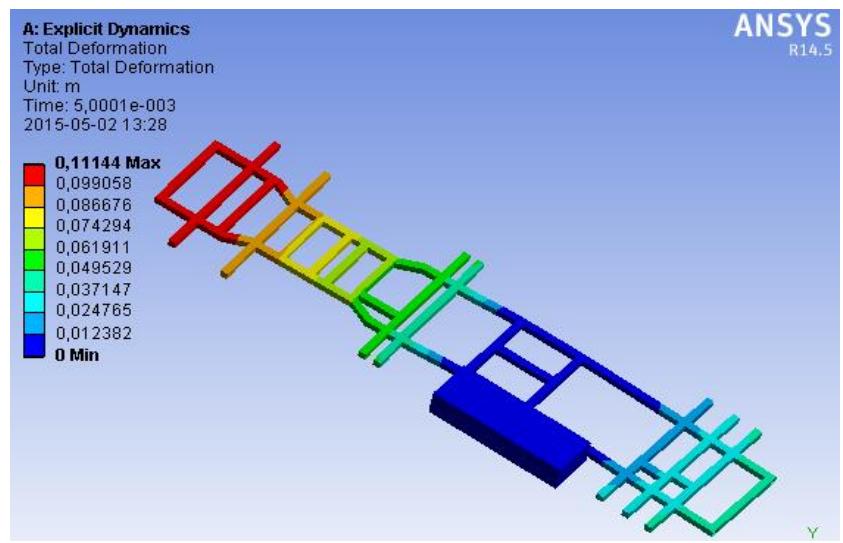

Fig. 6 The deformation of the frame in a basic minibus caused by an impact of an obstacle against the side of the frame 
The third modeling operation is accomplished for the frame of a basic minibus after an impact of a special $1.5 \mathrm{~m}$ wide obstacle that moves with the velocity of $50 \mathrm{~km} / \mathrm{h}$ against the minibus (Fig. 6).

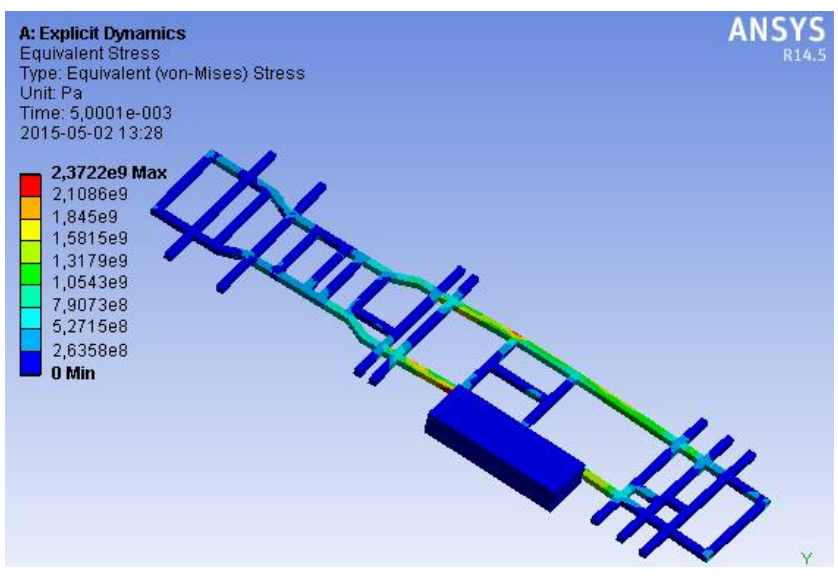

Fig. 7 The distribution of tensions in the frame of a basic minibus caused by an impact of an obstacle against the side of the frame

Upon analogous conditions, the forth modeling operation is accomplished for the frame of a low floor minibus after an impact of a special $1.5 \mathrm{~m}$ wide obstacle that moves with the velocity of $50 \mathrm{~km} / \mathrm{h}$ against the minibus (Fig. 8).

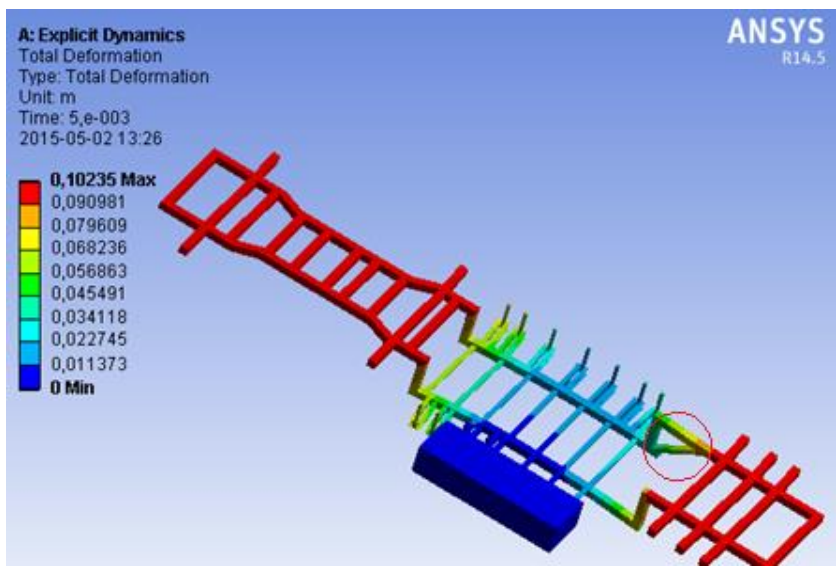

Fig. 8 The deformation of the frame in a low floor minibus caused by an impact of an obstacle against the side of the frame

The maximum deformation of the frame in a low floor minibus is $102.3 \mathrm{~mm}$ (Fig. 8). The difference between the values of deformations is caused by a supplemental frame protection structure in a low floor minibus that protects the principal structure of the frame and reduces its deformations. When the frame knocks against an obstacle, the appeared maximum tensions are equal to $278 \mathrm{MPa}$ (Fig. 9). The difference between the values of frame tensions in a basic minibus and a low floor minibus (almost ten times) is predetermined by the circumstance that the frame in a low floor minibus is deformed in several planes (thus reducing the tensions caused by the impact), whereas the frame in a basic minibus is deformed in a single plane only.

After assessment of the results obtained upon applying „Ansys" program, it may be stated that the tensions in the frame of a low floor minibus caused by its knocking against an obstacle (both in a case of a frontal impact and in a case of a lateral impact) are 10 times less, as compared to the tensions appeared in the frame of a basic minibus. It may be explained by the circumstance that the frame of a low floor minibus is not situated in a single plane and includes a larger number of connecting elements, so the tensions are not concentrated in a single point, but are distributed in the whole subframe.

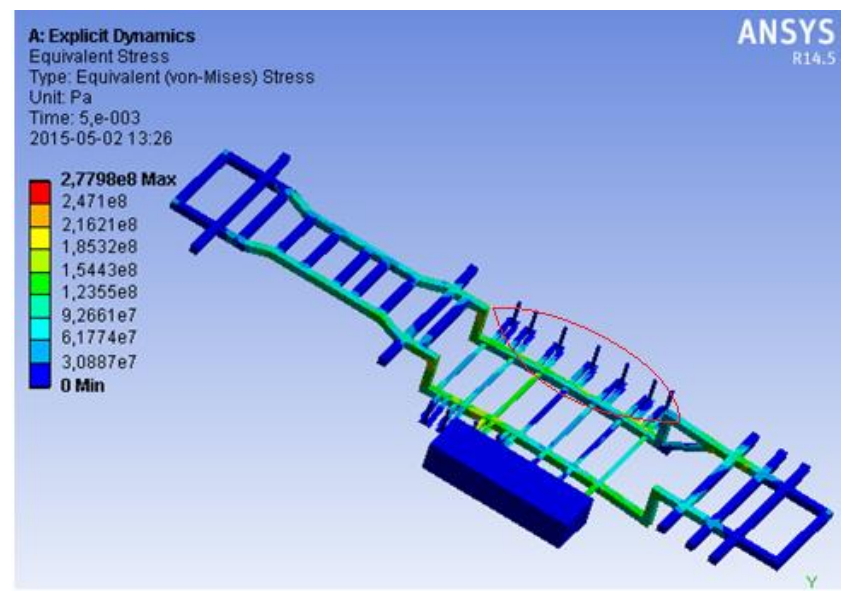

Fig. 9 The distribution of tensions in the frame of a low floor minibus caused by an impact of an obstacle against the side of the frame

In the case of front impact, the most dangerous place in a factory frame is on the left side of the front axle. In the case of front collision in a low-floor frame the most dangerous place is on the left side, but in this case in front of the front axle. In the case of side impact case, the most dangerous place in a factory frame is on the left side in the middle of a frame. In the case of side collision in low-floor frame the most dangerous place is on the left side too, but in this case dangerous place is lower.

The deformations of the frames are very much alike in all subframes. Their differences are about $1 \%$.

\section{Conclusions}

The deformation of the frame in a low floor minibus caused by a frontal impact is less by $0.02 \%$ than the deformation of the frame in a basic minibus. So, it may be stated that the construction of the lowered frame is not weaker, as compared to the construction of the basic frame.

The tensions in the frame of a basic minibus caused by a frontal impact exceed the tensions in the frame of a low floor minibus 10 times.

In a case of a lateral impact, the deformation of the frame in a low floor minibus is $102 \mathrm{~mm}$ and the deformation of the frame in a basic minibus is $114 \mathrm{~mm}$.

The tensions in the frame of a low floor minibus caused by its knocking against an obstacle (both in a case of a frontal impact and in a case of a lateral impact) are 10 times less, as compared to the tensions appeared in the frame of a basic minibus. Such a difference is caused by the circumstance that the basic frame is deformed in a single plane, whereas the lowered frame - in several planes. So, the lowered frame on its deformation bends at the overlap of planes and causes considerably less tensions.

In the case of front impact, the most dangerous place in a factory frame is on the left side of the front axle and in a low-floor frame is on the left side, but in this case 
in front of the front axle. In the case of side impact, the most dangerous place in a factory frame is on the left side in the middle of a frame and in a low-floor frame is on the left side too, but in this case dangerous place is lower.

The obtained results of computer-aided modeling may be included in today methodology for assessing safety and reliability of a construction upon certain conditions.

The developed computer models may be used in manufacturing low floor minibuses and in accomplishment of various modifications of the frame.

The developed computer models of the frames may be used for safety tests of modified frame constructions.

The computer models of the frames would enable an assessment of the safety and strength of a structure following its reconstruction after a traffic event.

\section{References}

1. Žuraulis, V.; Sokolovskij, E.; Matijošius, J. 2013. The opportunities for establishing the critical speed of the vehicle on research in its lateral dynamics, Eksploatacja i Niezawodnosc - Maintenance and Reliability 15 (4): 312-318.

2. Sokolovskij, E.; Prentkovskis, O. 2013. Investigating traffic accidents: the interaction between a motor vehicle and a pedestrian, Transport 28 (3): 302-312. http://dx.doi.org/10.3846/16484142.2013.831771.

3. Jeyakumar, P.D.; Devaradjane, G. 2012. Improvement of the Frontal Structure of a Bus for Crash Accidents, Transportation Systems 11:183-187. http://dx.doi.org/10.1115/IMECE2012-86869.

4. Khatri, F.; Jain, S.; Bhaskar, P. 2014. Crash Test Simulation and Analysis of a Passenger Bus Frame, International Journal of Engineering Trends and Technology (IJETT) 11(1): 49-53. http://dx.doi.org/10.14445/22315381/IJETT-V11P210.

5. Parka, C.K.; Kana, C. D.; Hollowell, W. T. 2014. Evaluation of crashworthiness of a carbon-fibrereinforced polymer (CFRP) ladder frame in a body-onframe vehicle, International Journal of Crashworhiness 19(1): $27-41$. http://dx.doi.org/10.1080/13588265.2013.830940.

6. Horstemeyera, M.F.; Li, H.; Siervogel, J.; Kwasniewski, L.; Wekezer, J.; Christian, B.; Roufa, G. 2007. Material and structural crashworthiness characterization of paratransit buses, International Journal of Crashworthiness 12(5): 509-520. http://dx.doi.org/10.1080/13588260701483680.

7. Kuznetsov, M.A; Zernin, E.A. 2011. Nanotechnologies and nanomaterials in welding production, Welding International 26(4): 311-313. http://dx.doi.org/10.1080/09507116.2011.606158.

8. Gombor, B. 2005. Dynamic analysis of a bus body frame: determination of the loads and stresses, Vehicle System Dynamics 43(11): 807-822. http://dx.doi.org/10.1080/00423110500273400.

9. Noaimadudin, W.M.K.; Nor, H.S.; Amir, R.Ab.G.; Nik, R.A.; Khairul, I.A.J. 2013. Modelling and Simulation of a Single Deck Bus Subjected to Rollover Crash Loading, Applied Mechanics and Materials 393: 453459.

http://dx.doi.org/10.4028/www.scientific.net/AMM. 393.453.

10. Honglei, M.; Bingkun, L.; Shizhong, J.; Yanqiang,
B.; Yanhua, X.; Chengwen, T.; Xiaodong, Y.; Huiliang, D. 2011. Simulation analysis for the safety protection of cervical vertebra under unusual landing impact, International Journal of Crashworhiness 16(5): 469-743.

http://dx.doi.org/10.1080/13588265.2011.593977.

11. Dzerkelis, V.; Bazaras, Z.; Sapragonas, J.; Lukoševičius, V. 2012. Investigation of the experimental car body in static bending and torsion, Mechanika 18(4): 392-397.

http://dx.doi.org/10.5755/j01.mech.18.4.2345.

12. Sapragonas, J. 2013. Transporto priemonių kèbulai. Kaunas: Kauno technologijos universitetas. 208 p.

13. Mohd K. N. 2015. Rollover Analysis of Heavy Vehicle Bus, Universiti Tun Hussein Onn Malaysia. Vol. 660: 633-636. http://dx.doi.org/10.4028/www.scientific.net/AMM. 660.633 .

14. Marianski M.; Szosland A. 2012. Research on the strenght of Standard bus bodeis at rollover on the side, Technikal University of Lodz: 29-41.

15. Manjinder S. S. 2013. Frontal crash of bus, Altair Technology Conference. 1-14.

\section{T. Pravilonis, E. Sokolovskij, V. Surblys}

\section{THE ANALYSIS OF DEFORMATIONS OF THE FRAME IN A BASIC MINIBUS AND A LOW FLOOR MINIBUS}

S u m m a r y

In the paper, the structures of frames and the methods for calculation of their resistance are reviewed. A frame of a basic minibus and a frame of a low floor minibus are examined and analyzed herein. Computer-aided modeling of the frames are carried out. The structures of the frames are assessed while simulating their deformations caused both by frontal and lateral impacts against the frames. In addition, tensions, deflections and deformations appeared in the frames were assessed and compared.

Keywords: minibus, modelling, deflection, deformation, frame.

Received March 29, 2016 Accepted June 08, 2017 